\title{
A Novel Band-Stop Filter with Band-Pass, High-Pass, and Low-Pass Negative Group Delay Characteristics
}

\author{
Aixia Yuan $\mathbb{D}$, ${ }^{1,2}$ Shaojun Fang $\mathbb{D}^{1},{ }^{1}$ Zhongbao Wang $\mathbb{D}^{1},{ }^{1}$ Hongmei Liu $\mathbb{D}^{1},{ }^{1}$ \\ and Hongjun Zhang $\mathbb{D}^{2}$ \\ ${ }^{1}$ School of Information Science and Technology, Dalian Maritime University, Dalian 116026, China \\ ${ }^{2}$ School of Information Science and Engineering, Dalian Polytechnic University, Dalian 116034, China \\ Correspondence should be addressed to Shaojun Fang; fangshj@dlmu.edu.cn
}

Received 11 August 2021; Revised 6 October 2021; Accepted 3 November 2021; Published 22 November 2021

Academic Editor: Shah Nawaz Burokur

Copyright (c) 2021 Aixia Yuan et al. This is an open access article distributed under the Creative Commons Attribution License, which permits unrestricted use, distribution, and reproduction in any medium, provided the original work is properly cited.

A band-stop filter with three different negative group delay functions in the passband, namely, band pass, high pass and low pass, is proposed, which has small insertion loss. The capacitance, inductance, and resistance meet different conditions, and the circuit can realize three different negative group delay characteristics. The theoretical calculation and equation derivation are given. A band-stop filter with negative group delay function is fabricated, and the measured results are basically consistent with the simulation results. The correctness of the design is verified.

\section{Introduction}

Band-stop filters (BSFs) are used for blocking undesired signals in RF/microwave systems [1]. At present, much work has been done on band-stop filters [2-15]. Extended passband band-stop filter cascade with continuous $0.85-6.6 \mathrm{GHz}$ coverage is presented in [2]. Compact wideband band-stop filters with five transmission zeros are depicted in [3].

The research on filters is presented in a recently published work. Compact low-pass and dual-band band-pass filters with controllable transmission zero/center frequency/ passband bandwidth are proposed in [16]. The position of transmission zeros/center frequencies and $3 \mathrm{~dB}$ bandwidth characteristics can be separately controlled by varying the physical parameter of the designed filter structure. In [17], a compact D-CRLH resonator for low-pass filters with wide rejection band, high roll-off, and transmission zeros is proposed. The filter has wide rejection band bandwidth with three transmission zeros (TZs). The filter bandwidth and TZ frequencies are controlled by the D-CRLH element values, and the filter has minimum insertion loss in passband, high roll-off rate, and good figure of merit. In [18], miniaturized quad-band filters with improved selectivity using split ring resonators and metallic strips are proposed. The operating frequency of the proposed filter structure can be controlled with the variation in the length ratio of resonators.

As the performance index of filters, group delay affects the performance of communication systems [19,20]. The methods to reduce the group delay based on the all-pass network are designed in [21, 22]. Negative group delay (NGD) technology has attracted attention for reducing the influence of group delay. An equalization technique based on negative group delay is proposed in $[23,24]$, which can reconstruct the signals changed by time delay. The NGD circuits are realized by using series, shunt RLC resonators, or microwave regime. Although some active schemes of NGD circuits have been conceived, passive realizations have attracted more interest due to their higher simplicity [25]. Passive band-pass, low-pass, and high-pass NGD circuit topologies are presented in [26-28].

Negative group delay is gradually applied to filters. A class of NGD band-stop filter (BSF) circuits with inputreflectionless behavior are presented in [25], cancelling the undesired RF-power reflections that can adversely affect preceding active tags. In [29], reflective BSFs are designed with enhanced negative group delay bandwidth (NBW), 
where an additional impedance transformer is required to obtain good in-band matching. An absorptive band-stop filter is proposed and synthesized with prescribed NGD and NBW in [30].

At present, band-stop filters with negative group delay function generally achieve band-pass negative group delay, the insertion loss is large, and the signal has great attenuation. The NGD property is usually attained at the expense of significant signal-attenuation levels in lossy passive realizations of NGD circuits. In this paper, the LC band-stop filter with negative group delay of band pass, high pass and low pass is designed, and the insertion loss in the frequency range of negative group delay is improved.

This paper consists of six main parts. Section 2 introduces the structure of this circuit. The equations of bandstop filters satisfying different negative group delays are analyzed. The influence of each element value on the bandpass negative group delay is given. Section 3 discusses highpass negative group delay in the band-stop filter's passband. In Section 4, low-pass negative group delay in the band-stop filter's passband is analyzed. In Section 5, the theory, simulation, and measurement are carried out. The final part of the paper is conclusion.

\section{Band-Stop Filter Design with Negative Group Delay Function}

The capacitor $C_{1}$ and inductor $L_{1}$ are connected in parallel to form a simple band-stop filter with an impedance value of $Z_{1}$, as shown in Figure 1. The impedance value $Z_{1}$ is given in equation (1). The transfer function $S_{21(Z 1)}$ is given in equation (2), where $Z_{0}$ is the characteristic impedance. The quality factor of the filter is $Q=\left(f_{0} / \mathrm{BW}_{3 \mathrm{~dB}}\right) . f_{0}$ is the resonant frequency of the filter. $\mathrm{BW}_{3 \mathrm{~dB}}$ is the $3 \mathrm{~dB}$ bandwidth. The higher the $Q$ value, the narrower the bandwidth.

When there are only $L_{1}$ and $C_{1}$ in Figure 1, the group delay is calculated as shown in equation (3). When $\omega>0, L_{1}$ and $C_{1}$ are taken at any value, the group delay of the circuit is always positive, and there is no negative group delay. That is, $\tau_{1}(\omega)>0$.

$$
\begin{aligned}
& Z_{1}=\frac{1}{\mathrm{SC}_{1}+\left(1 / \mathrm{SL}_{1}\right)}, \\
& S_{21\left(Z_{1}\right)}=\frac{2 Z_{0}}{2 Z_{0}+Z_{1}}, \\
& \tau_{1}(\omega)=\frac{\partial \angle S_{21}\left(Z_{1}\right)}{\partial \omega}=\frac{2 L_{1} Z_{0}\left(L_{1} C_{1} \omega^{2}+1\right)}{4 L_{1}^{2} C_{1}^{2} Z_{0}^{2} \omega^{4}-8 L_{1} C_{1} Z_{0}^{2} \omega^{2}+L_{1}^{2} \omega^{2}+4 Z_{0}^{2}} . \\
& \qquad S_{21}=\frac{Z_{0}+Z_{1}+Z_{0}^{2} / Z_{2}+Z_{0}\left(1+\left(Z_{1} / Z_{2}\right)\right)}{}, \\
& \text { egative group delay circuit with } \\
& \text { added on the left side of the } \\
& \text { transfer function of the whole }
\end{aligned}
$$

Compared with $S_{21(Z 1)}$ and $S_{21}$, the passband and stopband of the simple band-stop filter and negative group delay band-stop filter do not change. Only the attenuation of $S_{21(Z 1)}$ and $S_{21}$ is different. When $L_{1}=3.9 \mathrm{nH}, C_{1}=120 \mathrm{pF}$, $L_{2}=970 \mathrm{nH}, C_{2}=1.6 \mathrm{pF}$, the simulations are as shown in Figures 2 and 3 .

When $\tau_{2}(\omega)=0$ and $R_{1}=R_{2}=Z_{0}=50 \Omega$, according to equation (6), two significant frequency values are calculated, which are, respectively, given in equations (9) and (10). $f_{0}$ represents the frequency corresponding to the minimum value of negative group delay in equation (11). The circuit with impedance $Z_{2}$ shown in Figure 1 is a band-pass negative group delay circuit if equation (12) is satisfied. It is a highpass negative group delay circuit if equation (13) is satisfied. It is a low-pass negative group delay circuit if equation (14) is satisfied.

After adding the negative group delay circuit with the impedance of $Z_{2}$ to the band-stop filter with the impedance of $Z_{1}$, if $\left(1 / \sqrt{L_{1} C_{1}}\right) \neq\left(1 / \sqrt{L_{2} C_{2}}\right)$ and equations (12)-(14) 


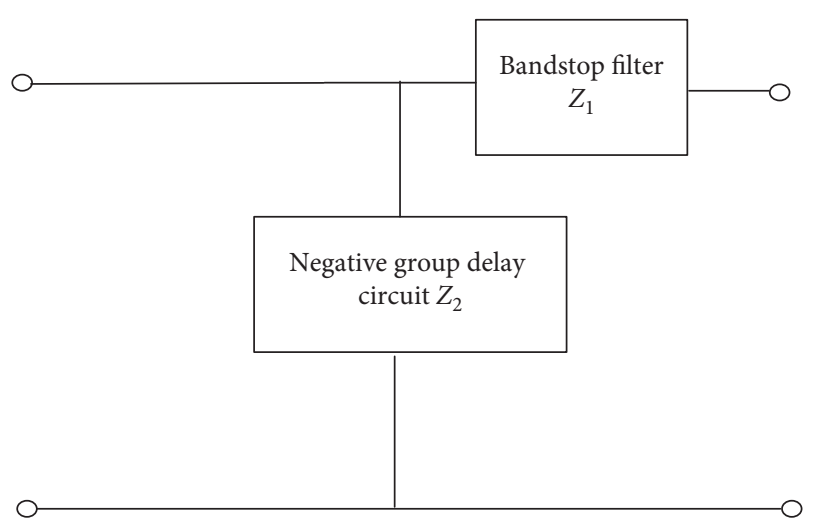

(a)

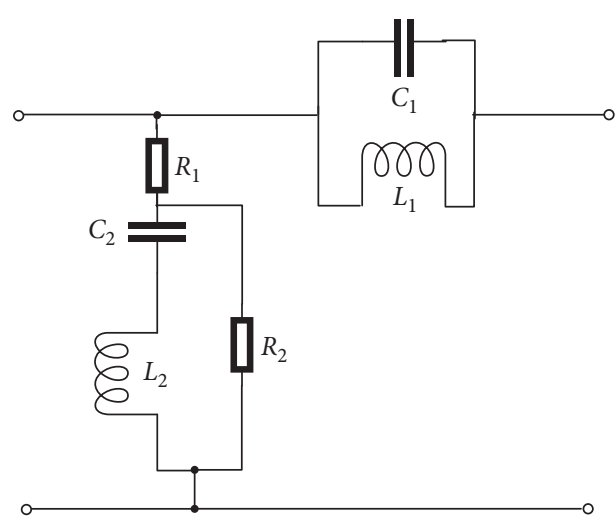

(b)

FIgURE 1: (a) Block diagram of the band-stop filter with negative group delay. (b) The circuit of the band-stop filter with negative group delay.

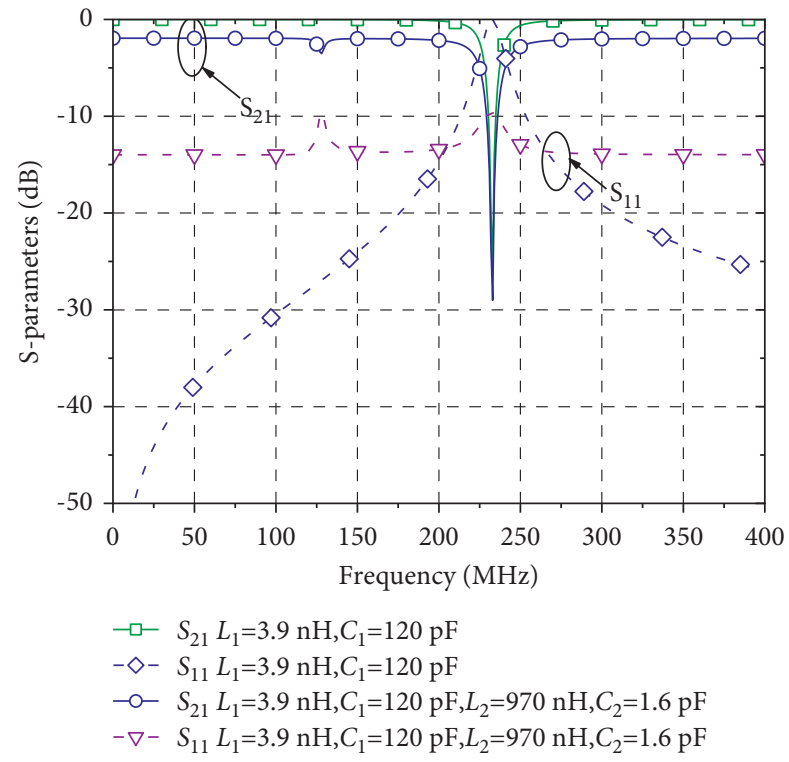

FIgURE 2: $S$ parameters of the band-stop filter and band-pass negative group delay band-stop filter.

are satisfied, respectively, the whole circuit can realize three different negative group delay band-stop filters of band pass, high pass, and low pass. The negative group delay band-stop filter is only attenuated by $1.9 \mathrm{~dB}$ compared with the original band-stop filter, but the negative group delay transmission of some signals in the passband is realized, and the delay performance of the filter is improved.

$$
\begin{aligned}
& f_{1}=\frac{\sqrt{375 C_{2}^{2}-5 \sqrt{15} \sqrt{C_{2}^{3}\left(375 C_{2}+2 L_{2}\right)}+C_{2} L_{2}}}{2 \pi C_{2} L_{2}}, \\
& f_{2}=\frac{\sqrt{375 C_{2}^{2}+5 \sqrt{15} \sqrt{C_{2}^{3}\left(375 C_{2}+2 L_{2}\right)}+C_{2} L_{2}}}{2 \pi C_{2} L_{2}}, \\
& f_{0}=\sqrt{f_{1} f_{2}},
\end{aligned}
$$

$$
\begin{aligned}
& \left\{\begin{array}{l}
\tau_{2}(\omega)>0(\omega \approx 0), \\
f_{2}-f_{0} \approx f_{0}-f_{1},
\end{array}\right. \\
& \left\{\begin{array}{l}
\tau_{2}(\omega) \geq 0(\omega \approx 0), \\
f_{2}-f_{0} \gg f_{0}-f_{1},
\end{array}\right.
\end{aligned}
$$

$$
\left\{\begin{array}{l}
\tau_{2}(\omega)<0(\omega=0), \\
\text { there is only one real solution }\left(\tau_{2}(\omega)=0\right) .
\end{array}\right.
$$

2.1. Band-Stop Filter with Band-Pass Negative Group Delay at Different $L_{2}$ Values. When $C_{1}, C_{2}$, and $L_{1}$ are fixed and $R_{1}=R_{2}=Z_{0}=50 \Omega$, the negative group delay circuit presents band-pass negative group delay. With the decrease in the inductance $L_{2}$ in the negative group delay circuit, the 


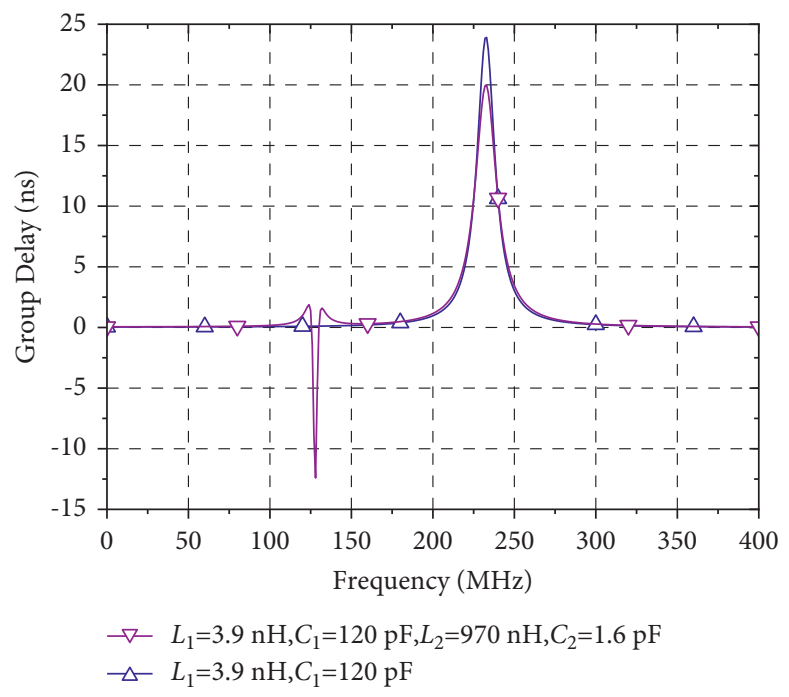

FIGURE 3: Group delay of the band-stop filter and band-pass negative group delay band-stop filter.

TABLE 1: Element values and performance indexes of the band-stop filter with different $L_{1}$ values when band-pass negative group delay occurs.

\begin{tabular}{lcccccc}
\hline$C_{1}(\mathrm{pF})$ & $L_{1}(\mathrm{nH})$ & $R_{1}, R_{2}(\Omega)$ & $C_{2}(\mathrm{pF})$ & $L_{2}(\mathrm{nH})$ & $f_{0}(\mathrm{MHz})$ & $\tau\left(f_{0}\right)(\mathrm{ns})$ \\
\hline 120 & 3.9 & 50 & 1.6 & 970 & 128 & -12.41 \\
120 & 3.9 & 50 & 1.6 & 470 & 184 & -5.77 \\
120 & 3.9 & 50 & 1.6 & 120 & 363 & -1.52 \\
\hline
\end{tabular}

$f_{0}$ is the frequency of the minimum of negative group delay. $\tau\left(f_{0}\right)$ is the minimum of negative group delay at the frequency $f_{0}$. IL is the insertion loss at $f_{0}$.

minimum negative group delay in the passband of the bandstop filter increases and it satisfies equation (15). The larger the inductance $L_{2}$ is, the smaller the negative group delay will be. The frequency of the minimum of negative group delay is about $1 / 2 \pi \sqrt{L_{2} C_{2}}$. The circuit appears as a bass-pass NGD according to the values of components in Table 1 . The bandpass negative group delay and $S_{21}$ at different values are shown in Figures 4 and 5, respectively.

$$
\tau_{3}(\omega)=\frac{M}{N}
$$

Here, $\quad M=35.3 L_{2}^{4}-7.18 \times 10^{28} L_{2}^{3}+8.38 \times 10^{20}$ $L_{2}^{2}+3.63 \times 10^{-6} L_{2}$ and $N=1.3 \times 10-24 L_{2}^{4}-5.38 \times 10^{3} L_{2}^{3}$ $+5.38 \times 10^{30} L_{2}^{2}-4.19 \times 10^{22} L_{2}+8.19 \times 10^{13}$.

\subsection{Analyzing the Influence of $C_{2}$ on Band-Stop Filters with} Band-Pass Negative Group Delay. Compared with Table 1, the $C_{2}$ value of the negative group delay circuit is changed, while the other element values remain unchanged. The performance indexes of negative group delay of the bandstop filter are shown in Table 2. In the passband of the bandstop filter, the minimum value of negative group delay changes little. Due to the change in $C_{2}$ value, the frequency of minimum negative group delay changes. It can be seen from Tables 1 and 2 that there is negative group delay in the passband of the band-stop filter. In the negative group delay circuit, the influence of capacitor $C_{2}$ on the group delay is small and the influence of inductance $L_{2}$ on the minimum

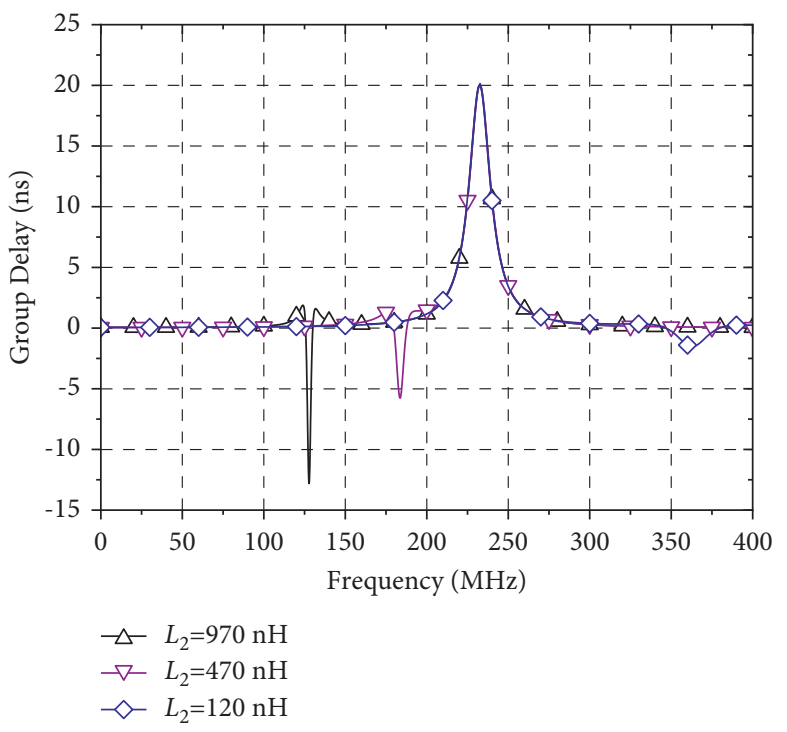

FIgURE 4: Negative delay of band pass in band-stop filter with different $L_{2}$.

negative group delay is large. The resonant frequency of the band-stop filter is $233 \mathrm{MHz}$, and the frequency of the minimum negative group delay avoids the value near $233 \mathrm{MHz}$. At this time, the negative group delay cannot be generated in the passband of the band-stop filter. The bandpass negative group delay and $S_{21}$ at different $C_{2}$ are presented in Figures 6 and 7, respectively. 


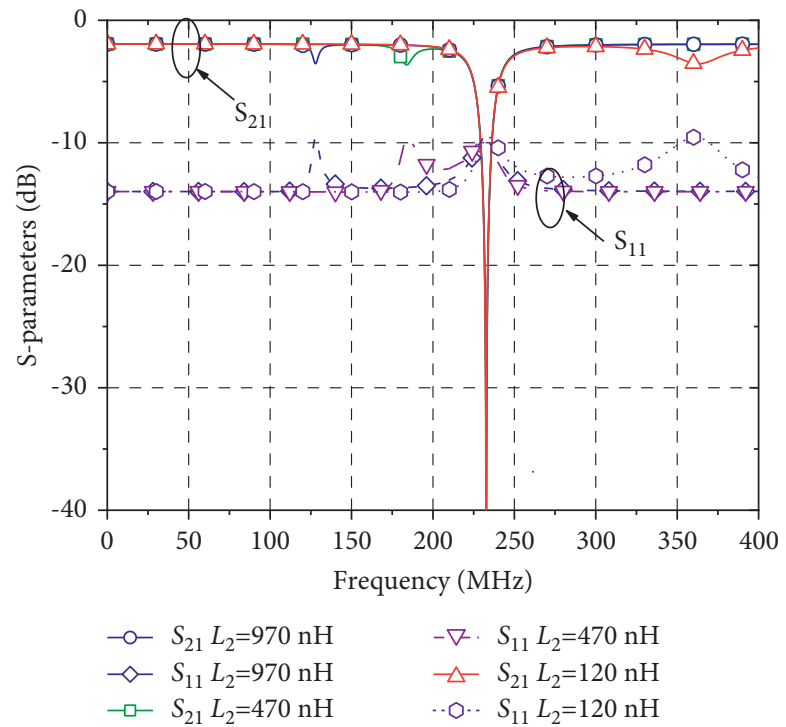

FIGURE 5: $S$ parameters of the band-stop filter with band-pass negative group delay at different $L_{2}$.

TABLE 2: Element value and performance index of band-stop filters with band-pass negative group delay when $C_{2}$ is changed.

\begin{tabular}{lccccccc}
\hline$C_{1}(\mathrm{pF})$ & $L_{1}(\mathrm{nH})$ & $R_{1}, R_{2}(\Omega)$ & $C_{2}(\mathrm{pF})$ & $L_{2}(\mathrm{nH})$ & $f_{0}(\mathrm{MHz})$ & $\tau\left(f_{0}\right)(\mathrm{ns})$ & $\mathrm{IL}(\mathrm{dB})$ \\
\hline 120 & 3.9 & 50 & 1.6 & 970 & 128 & -12.41 \\
120 & 3.9 & 50 & 16 & 970 & 40 & -11.78 & 3.5 \\
120 & 3.9 & 50 & 160 & 970 & 13 & -12.29 \\
\hline
\end{tabular}

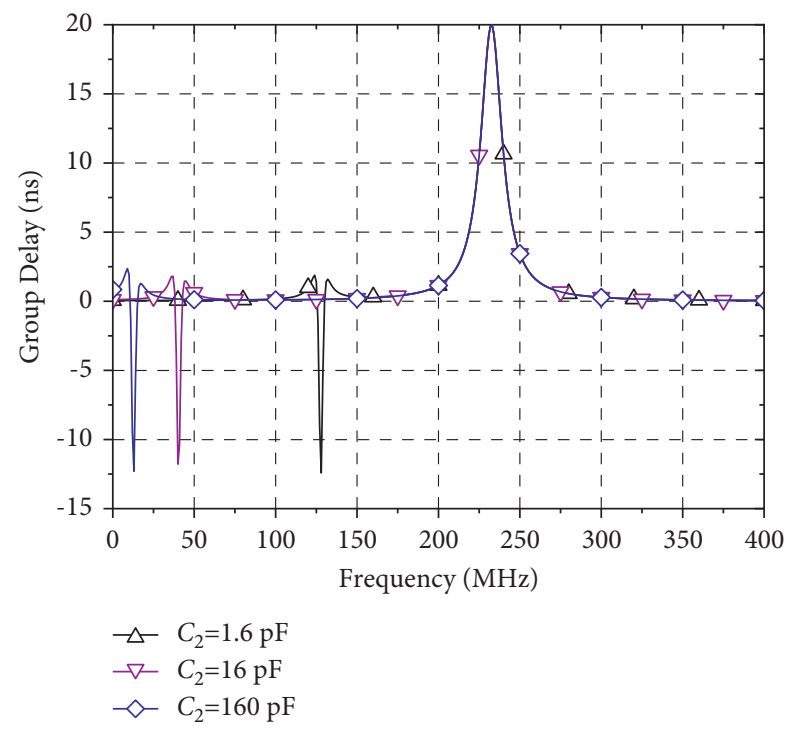

FIgURE 6: Negative delay of band pass in band-stop filter with different $C_{2}$ compared with Table 1 . 


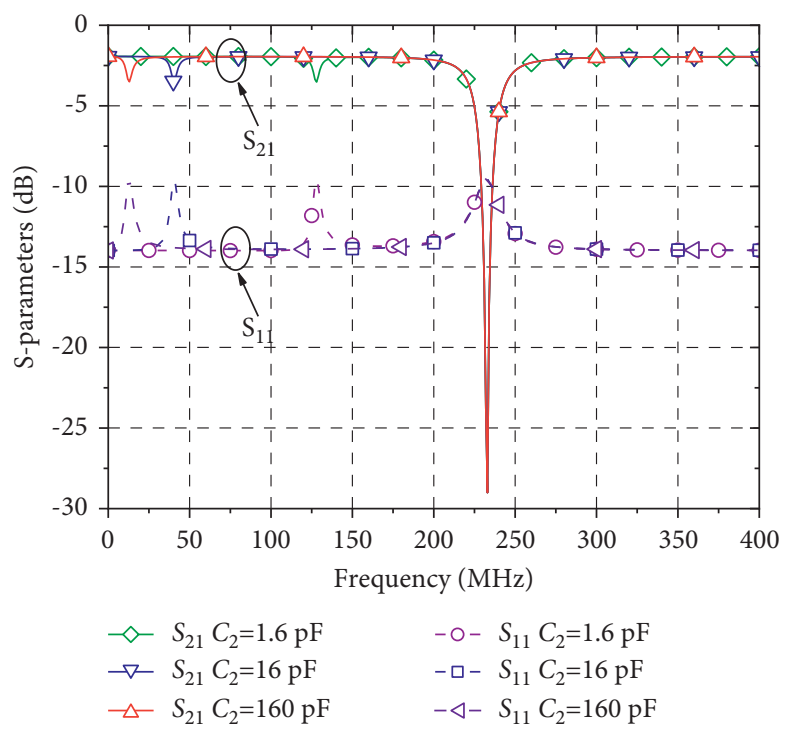

FIgURE 7: $S$ parameters of the band-stop filter with band-pass negative delay at different $C_{2}$.

TABLE 3: Element values and performance indexes of the band-stop filter with different $C_{1}$ values when band-pass negative group delay occurs.

\begin{tabular}{lccccccc}
\hline$C_{1}(\mathrm{pF})$ & $L_{1}(\mathrm{nH})$ & $R_{1}, R_{2}(\Omega)$ & $C_{2}(\mathrm{pF})$ & $L_{2}(\mathrm{nH})$ & $f_{0}(\mathrm{MHz})$ & $\tau\left(f_{0}\right)(\mathrm{ns})$ & $\mathrm{IL}(\mathrm{dB})$ \\
\hline 120 & 3.9 & 50 & 1.6 & 970 & 128 & -12.41 \\
160 & 3.9 & 50 & 1.6 & 970 & 128 & -12.36 \\
200 & 3.9 & 50 & 1.6 & 970 & 128 & -12.28 \\
\hline
\end{tabular}

TABLE 4: Element values and performance indexes of band-stop filter with different $L_{1}$ values when band-pass negative group delay occurs.

\begin{tabular}{lcccccc}
\hline$C_{1}(\mathrm{pF})$ & $L_{1}(\mathrm{nH})$ & $R_{1}, R_{2}(\Omega)$ & $C_{2}(\mathrm{pF})$ & $L_{2}(\mathrm{nH})$ & $f_{0}(\mathrm{MHz})$ & $\tau\left(f_{0}\right)(\mathrm{ns})$ \\
\hline 120 & 3.9 & 50 & 1.6 & 970 & 128 & -12.41 \\
120 & 6.8 & 50 & 1.6 & 970 & 128 & -12.18 \\
120 & 100 & 50 & 1.6 & 970 & 128 & -12.16 \\
\hline
\end{tabular}

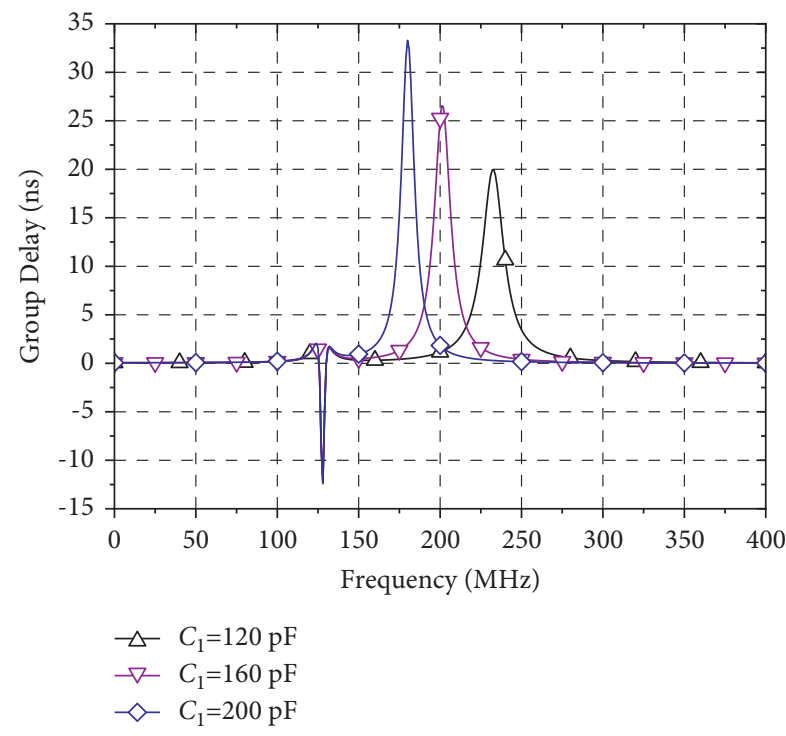

FIGURE 8: Negative delay of band pass in the band-stop filter with different $C_{1}$.
2.3. Analyzing the Influence of $C_{1}$ and $L_{1}$ on the Band-Stop Filter with Band-Pass Negative Group Delay. Compared with Table 2, changing the resonant frequency of the band-stop filter, that is, changing $C_{1}$ and $L_{1}$, and keeping $C_{2}, L_{2}, R_{1}$, and $R_{2}$ unchanged, the negative group delay value is basically unchanged. The data are depicted in Tables 3 and 4. At this time, only the resonant frequency of the band-stop filter changes and the negative group delay value in the passband and the corresponding negative group delay frequency remain unchanged.

The capacitor $C_{1}$ affects the group delay value of the band-stop filter at the resonant frequency, as shown in Figure 8. However, the inductor $L_{1}$ does not affect the group delay value of the band-stop filter at the resonant frequency, as shown in Figure 9. The characteristics of insertion loss and return loss with different $C_{1}$ and $L_{1}$ values are presented in Figures 10 and 11.

2.4. Analyzing the Influence of $R_{1}$ on the Band-Stop Filter with Band-Pass Negative Group Delay. The resistance $R_{1}$ has a great influence on the negative group delay. The frequency of the negative group delay in the passband of the band-stop 


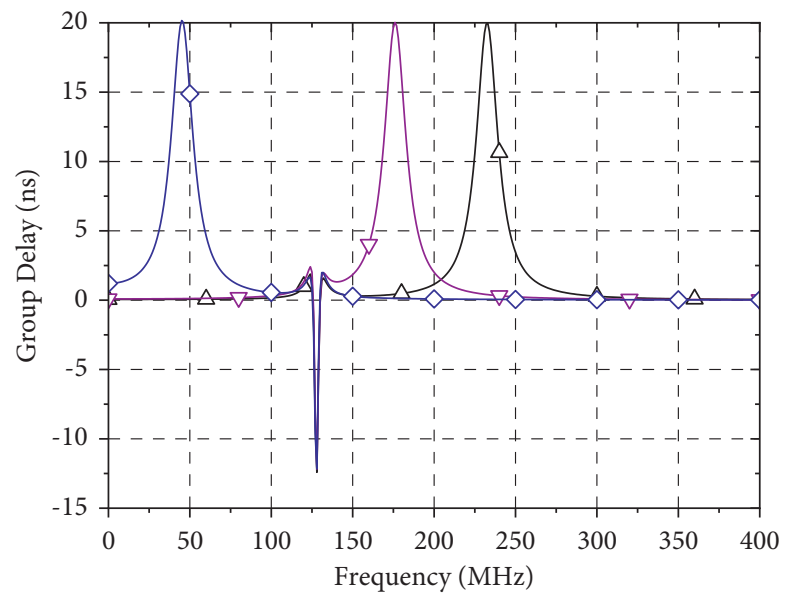

$$
\begin{aligned}
& \triangle L_{1}=3.9 \mathrm{nH} \\
& \nabla-L_{1}=6.8 \mathrm{nH} \\
& \diamond-L_{1}=100 \mathrm{nH}
\end{aligned}
$$

FIgUre 9: Negative delay of band pass in the band-stop filter with different $L_{1}$.

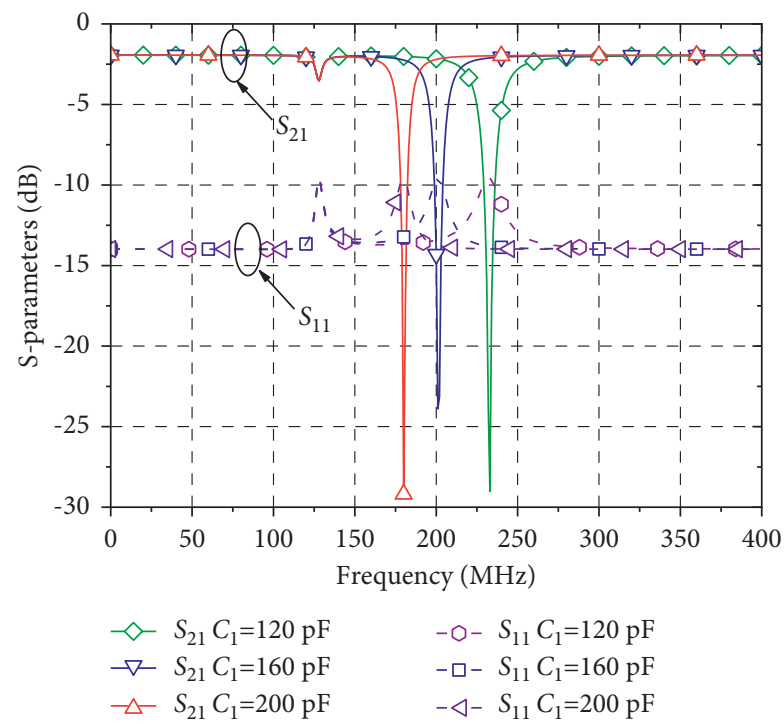

Figure 10: $S$ parameters of the band-stop filter with band-pass negative delay at different $C_{1}$.

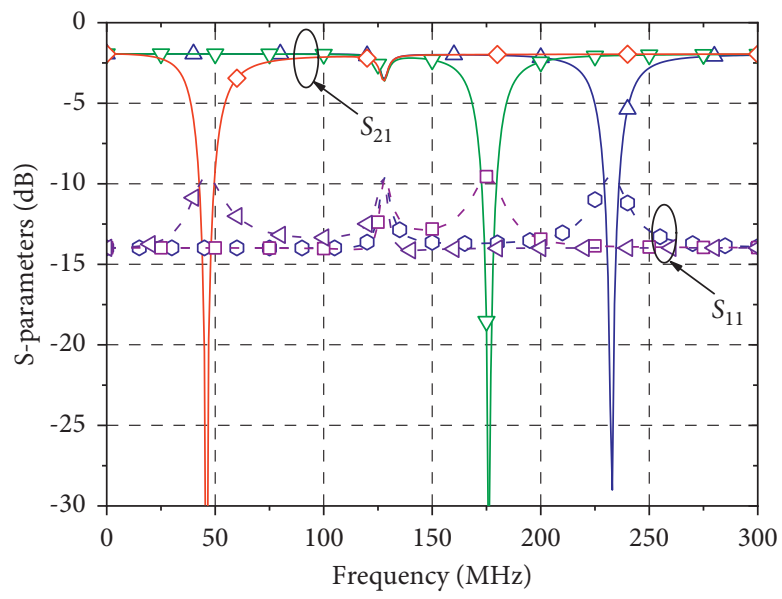

$$
\begin{array}{ll}
\triangleleft S_{21} L_{1}=3.9 \mathrm{nH} & -\bullet-S_{11} L_{1}=3.9 \mathrm{nH} \\
--S_{21} L_{1}=6.8 \mathrm{nH} & -\square-S_{11} L_{1}=6.8 \mathrm{nH} \\
\diamond-S_{21} L_{1}=100 \mathrm{nH} & -\triangleleft-S_{11} L_{1}=100 \mathrm{nH}
\end{array}
$$

FIgURE 11: $S$ parameters of band-stop filter with band-pass negative delay at different $L_{1}$. 
TABLE 5: Element values of the band-pass negative group delay circuit with different $R_{1}$ values.

\begin{tabular}{|c|c|c|c|c|c|c|c|}
\hline$C_{1}(\mathrm{pF})$ & $L_{1}(\mathrm{nH})$ & $R_{1}(\Omega)$ & $C_{2}(\mathrm{pF})$ & $L_{2}(\mathrm{nH})$ & $f_{0}(\mathrm{MHz})$ & $\tau\left(f_{0}\right)(\mathrm{ns})$ & IL (dB) \\
\hline 120 & 20 & 50 & 120 & 470 & 21 & -5.97 & 3.5 \\
\hline 120 & 20 & 30 & 120 & 470 & 21 & -13.82 & 5.3 \\
\hline 120 & 20 & 20 & 120 & 470 & 21 & -25.80 & 7.0 \\
\hline
\end{tabular}

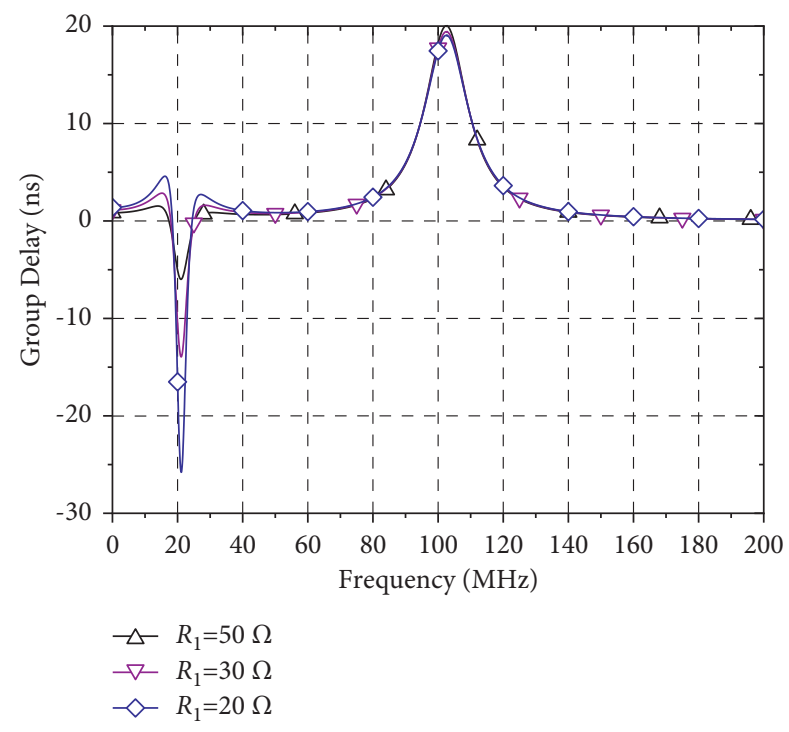

FIGURE 12: Negative delay of band pass in the band-stop filter with different $R_{1}$.

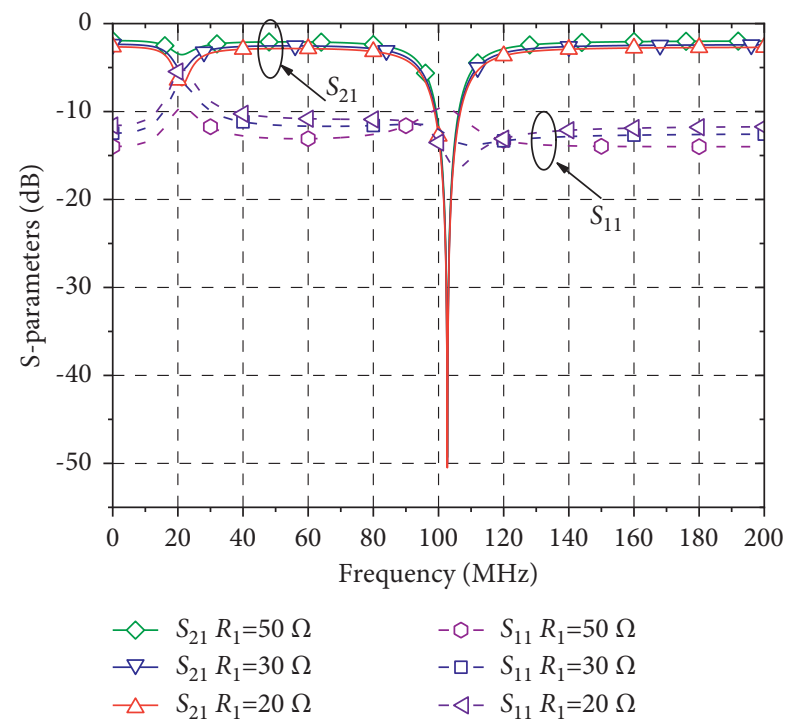

FIGURE 13: $S$ parameters of the band-stop filter with band-pass negative delay at different $R_{1}$. 


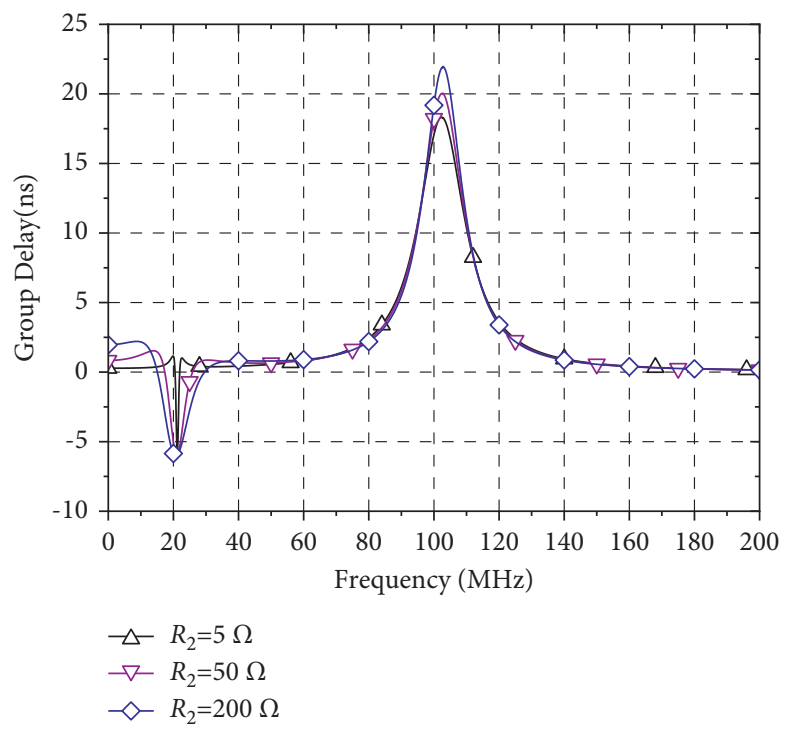

Figure 14: Negative delay of band pass in the band-pass filter with different $R_{2}$.

TABLE 6: Element values of the band-pass negative group delay circuit with different $R_{2}$ values.

\begin{tabular}{lccccc}
\hline$R_{1}(\Omega)$ & $R_{2}(\Omega)$ & $f_{0}(\mathrm{MHz})$ & $\tau\left(f_{0}\right)(\mathrm{ns})$ & IL $\left(f_{0}\right)(\mathrm{dB})$ & NGD band $(\mathrm{MHz}))$ \\
\hline 50 & 5 & 21 & -5.96 & 3.5 & 1.56 \\
50 & 50 & 21 & -5.98 & 3.5 & 9.28 \\
50 & 200 & 21 & -6.03 & 3.5 & 15.83 \\
\hline
\end{tabular}

TABLE 7: Element values of the high-pass negative group delay circuit with different $C_{2}$ values.

\begin{tabular}{|c|c|c|c|c|c|c|}
\hline$C_{1}(\mathrm{nF})$ & $L_{1}(\mathrm{nH})$ & $C_{2}(\mathrm{nF})$ & $L_{2}(\mathrm{nH})$ & $f_{\text {opt }}(\mathrm{kHz})$ & $\tau\left(f_{\text {opt }}\right)(\mathrm{ns})$ & IL $(\mathrm{dB})$ \\
\hline 1.5 & 120 & 15 & 3.9 & 670 & -7.71 & 3.1 \\
\hline 1.5 & 120 & 18 & 3.9 & 560 & -9.58 & 3.1 \\
\hline 1.5 & 120 & 22 & 3.9 & 460 & -12.07 & 3.1 \\
\hline
\end{tabular}

$f_{\text {opt }}$ refers to the frequency with the minimum negative group delay, $\tau\left(f_{\text {opt }}\right)$ corresponds to the minimum negative group delay at frequency $f_{\text {opt }}$, and insertion loss refers to the loss at $f_{\text {opt }}$ frequency. IL refers to insertion loss.

filter is the resonant frequency of the negative group delay circuit. The data are shown in Table 5. The group delay and insertion loss characteristics at different $R_{1}$ are shown in Figures 12 and 13.

2.5. Analyzing the Influence of $R_{2}$ on the Band-Stop Filter with Band-Pass Negative Group Delay. When $C_{1}=C_{2}=120 \mathrm{pF}$, $L_{1}=20 \mathrm{nH}$, and $L_{2}=470 \mathrm{nH}, R_{2}$ mainly affects the negative group delay bandwidth of the band-stop filter in the passband but has little effect on the minimum negative group delay, as depicted in Figure 14. With the increase in resistance $R_{2}$, the negative group delay bandwidth of the band-stop filter in the passband increases, as shown in Tables 6. The characteristics of insertion loss are shown in Figure 15. At the minimum negative group delay, the loss is only $3.5 \mathrm{~dB}$. The Figure of Merit (FOM) of designed filters is given in equation (16). When $R_{2}=200 \Omega$ in Table 6 , FOM $=0.0639$. where $\tau\left(f_{0}\right)$ represents the minimum negative group delay. $B_{\mathrm{NGD}}$ represents the band of NGD. $S_{21}\left(f_{0}\right)$ represents the insertion loss at frequency $f_{0}$.

$$
\mathrm{FOM}=\left|\tau\left(f_{0}\right)\right| \times B_{\mathrm{NGD}} \times\left|S_{21}\left(f_{0}\right)\right|,
$$

\section{High-Pass Negative Group Delay in Band- Stop Filter Passband}

According to the values of $L_{1}, L_{2}, C_{1}$, and $C_{2}$ in Table 7 and $R_{1}=R_{2}=50 \Omega$, the circuit presents a high-pass negative group delay circuit in band-stop filter passband. The condition for forming high-pass negative group delay in equation (13) is satisfied. The negative group delay decreases with the increase in capacitance while the inductance and resistance remain unchanged. The simulation results are shown in Figures 16 and 17.

\section{Low-Pass Negative Group Delay in the Passband of the Band-Stop Filter}

The circuit appears as a low-pass NGD circuit according to the values of components $L_{1}, C_{1}, R_{1}$, and $R_{2}$ in Table 8. According to equation (14), when the 


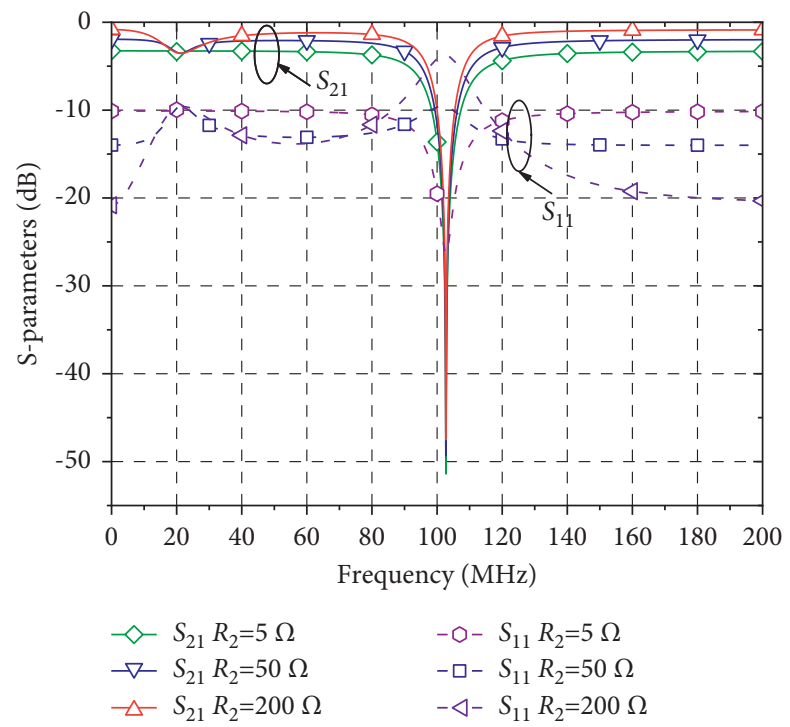

Figure 15: $S$ parameters of the band-stop filter with negative band-pass delay at different $R_{2}$.

TABLE 8: Element values of low-pass negative group delay circuits with different values of $L_{2}$.

\begin{tabular}{lcccccc}
\hline$C_{1}(\mathrm{pF})$ & $L_{1}(\mathrm{nH})$ & $R_{1}, R_{2}(\Omega)$ & $C_{2}(\mathrm{pF})$ & $L_{2}(\mathrm{nH})$ & $\tau(0)(\mathrm{ns})$ \\
\hline 120 & 3.9 & 50 & 0 & 470 & -3.08 & $\mathrm{IL}(\mathrm{dB})$ \\
120 & 3.9 & 50 & 0 & 390 & -2.54 & 3.5 \\
120 & 3.9 & 50 & 0 & 200 & -1.28 \\
\hline
\end{tabular}

$\tau(0)$ represents the minimum negative group delay $(f=0)$.

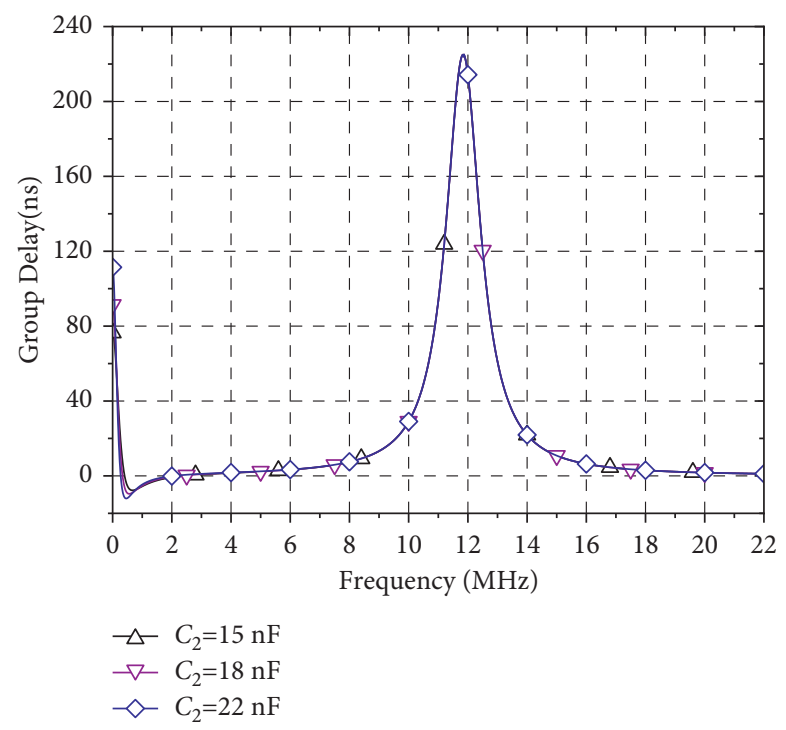

FIGURE 16: High-pass negative group delay in the band-stop filter passband.

inductance decreases, the negative group delay increases. The cutoff frequency and the bandwidth increase. The simulation results are shown in Figures 18 and 19, from which it can be seen that the influence of inductance on the parameters of the low-pass negative group delay circuit.

\section{Measurement and Discussion of Band-Pass NGD of Band-Stop Filter Circuits}

When the element values are, respectively, $C_{1}=C_{2}=120 \mathrm{pF}$, $L_{1}=20 \mathrm{nH}, L_{2}=470 \mathrm{nH}, R_{1}=R_{2}=50 \Omega$, and $Z_{0}=50 \Omega$, the circuit is fabricated according to the element values. It is 


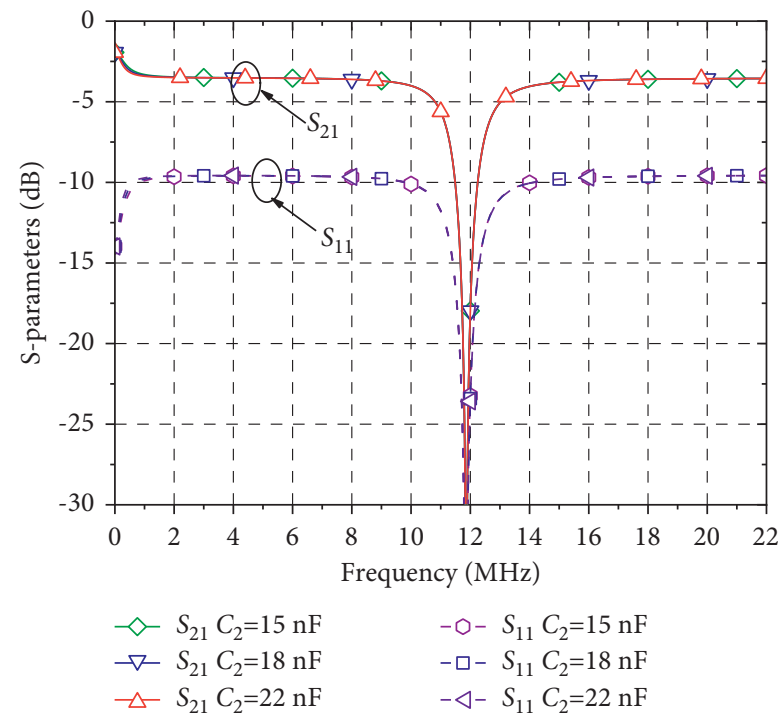

Figure 17: $S$ parameters of the band-stop filter with negative high-pass delay at different $C_{2}$.

TABLE 9: Comparison results of theory, simulation, and measurement.

\begin{tabular}{|c|c|c|c|c|c|c|}
\hline Comparison & $f_{0}(\mathrm{MHz})$ & NGD (ns) & $f(\mathrm{MHz})$ & GD (ns) & $\mathrm{IL}_{f 0}(\mathrm{~dB})$ & $\mathrm{IL}_{f}(\mathrm{~dB})$ \\
\hline Theo. & 21.3 & -5.9 & 102.3 & 20.0 & 3.5 & 27.2 \\
\hline Simu. & 21.3 & -3.9 & 100.3 & -30.4 & 3.3 & 11.8 \\
\hline Mear. & 21.3 & -3.1 & 100.3 & -47.2 & 3.1 & 14.5 \\
\hline
\end{tabular}

$f_{0}$ is the frequency at which the minimum negative group delay occurs in the passband of the band-stop filter. NGD represents the minimum negative group delay at frequency $f_{0}$. $f$ represents the resonant frequency of the band-stop filter. GD represents the group delay at frequency $f$. $\mathrm{IL}_{f 0}$ represents the insertion loss at frequency $f_{0} . \mathrm{IL}_{f}$ represents the insertion loss at frequency $f$.

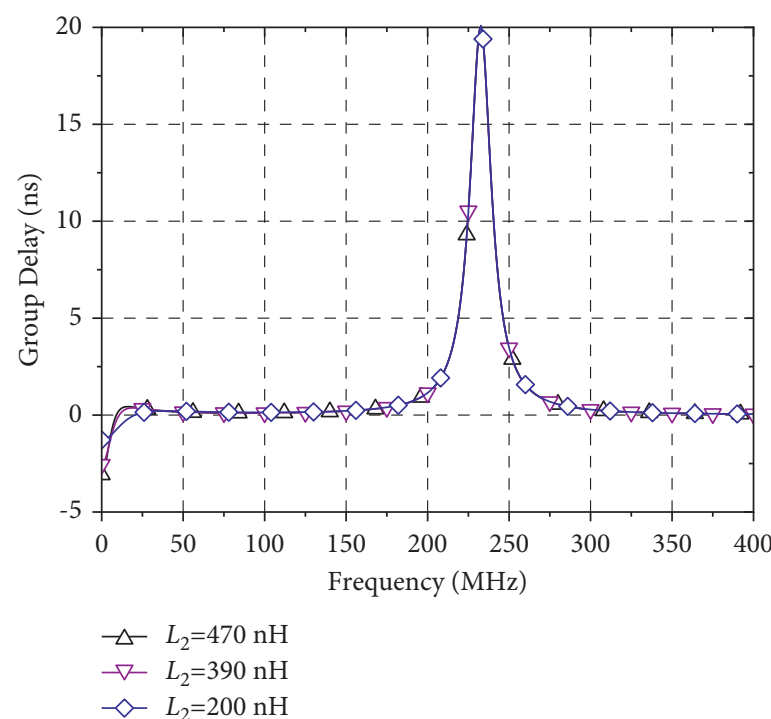

FIgURE 18: Low-pass negative group delay of the band-stop filter with different inductance values $\left(L_{2}\right)$.

shown in Figure 20. The conditions of forming a band-pass negative group delay in the passband of the band-stop filter are satisfied. The theoretical, simulated, and measured waveforms are shown in Figures 21 and 22. Due to the influence of parasitic parameters in the parallel circuit, the simulation results deviate from the theoretical calculation.
Compared with the simulation results, the group delay changes from positive to negative at the resonant frequency of the band-stop filter. The simulation results and the measured results are basically the same in the minimum negative group delay and the center frequency corresponding to the minimum negative group delay. 


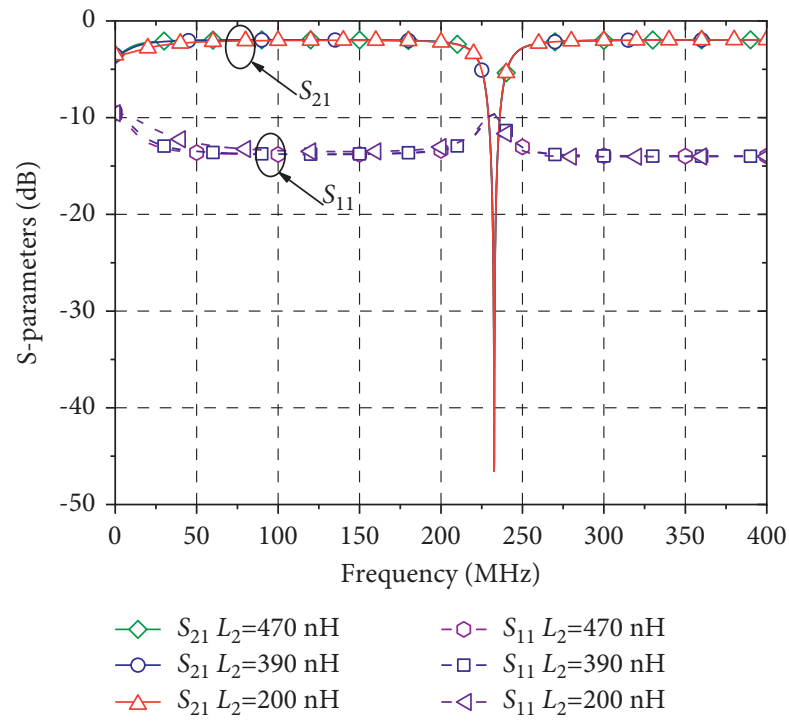

FIGURE 19: $S$ parameters of the band-stop filter with low-pass negative group delay circuit.

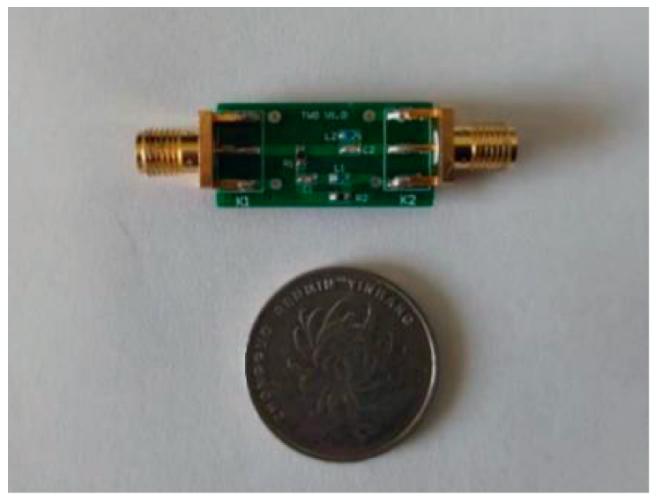

Figure 20: The fabricated band-stop filter circuit with band-pass negative group delay.

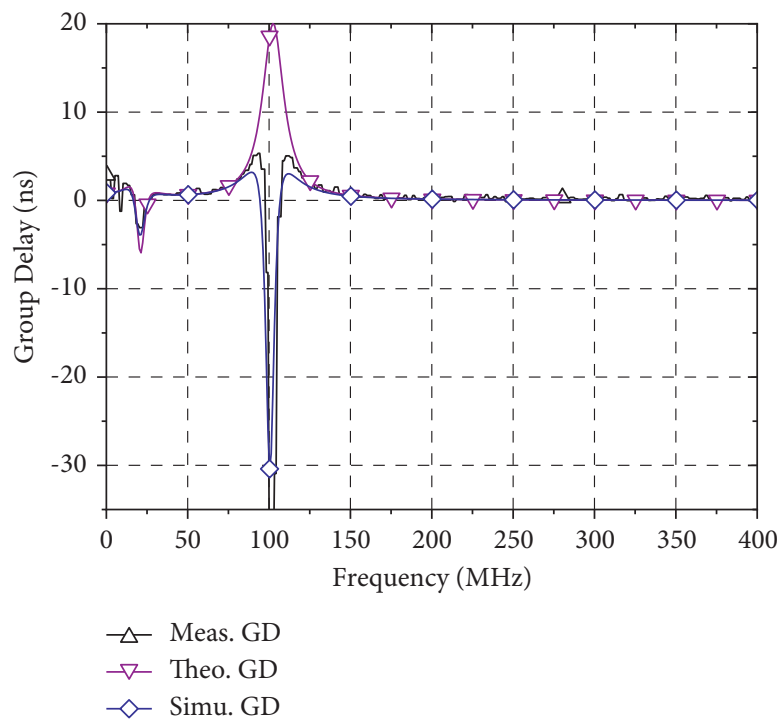

Figure 21: Band-pass negative group delay of the band-stop filter. 


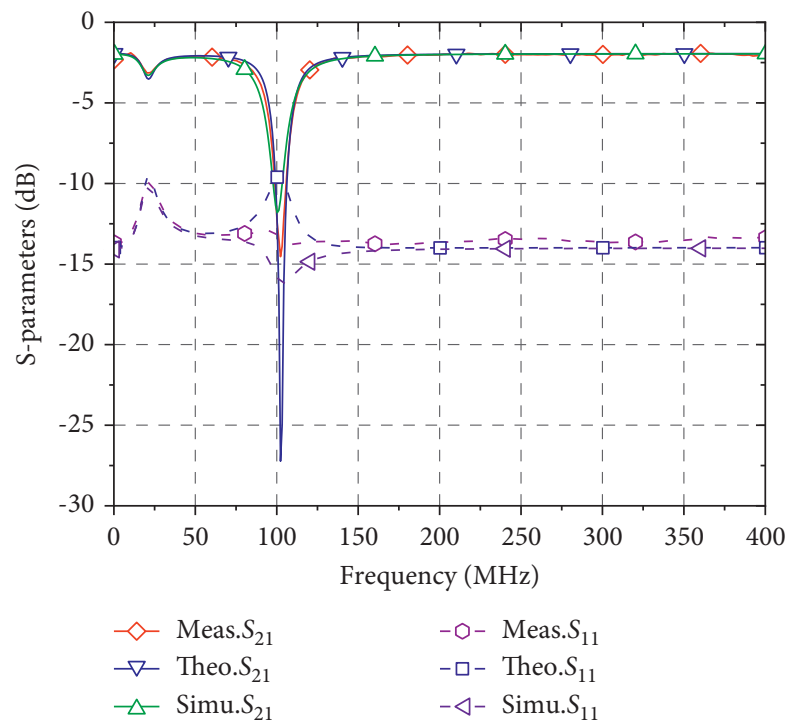

FIGURE 22: $S$ parameters of the band-pass negative group delay of the band-stop filter.

TABLE 10: Performance comparison between band-pass negative group delay in the passband of the band-stop filter and the proposed NGD band-stop filter.

\begin{tabular}{|c|c|c|c|c|c|}
\hline Literature & $f_{0}(\mathrm{GHz})$ & NGD (ns) & NGD band $(\mathrm{MHz})$ & IL (dB) & FOM \\
\hline [29] & 1.962 & -7.3 & 100 & 22.65 & 0.0511 \\
\hline$[30]$ & 1.99 & -6.5 & 105 & 22.6 & 0.0477 \\
\hline$[31]$ & 2.14 & -1.0 & 60 & 3.8 & 0.0384 \\
\hline [32] & 1.0 & -1.5 & 370 & 33 & 0.0111 \\
\hline$[33]$ & 2.14 & -0.034 & - & 6.05 & - \\
\hline This work & 0.0210 & -6.03 & 15.83 & 3.5 & 0.0639 \\
\hline
\end{tabular}

$f_{0}$ refers to the frequency at the minimum negative group delay. NGD (ns) refers to the minimum negative group delay. IL is the insertion loss.

The comparison results of theoretical, simulation, and measurement performance indicators are shown in Table 9.

The comparison of the band-pass negative group delay in the passband of the band-stop filter with the reported literature is shown in Table 10. Compared with other band-stop filters, the designed band-stop filter with band-pass negative group delay operates at a lower frequency. Compared with [33], the negative group delay is reduced by $5.996 \mathrm{~ns}$ and the insertion loss is decreased by about $2.55 \mathrm{~dB}$. Compared with [26], the insertion loss is decreased $19.15 \mathrm{~dB}$. Compared with [27], the insertion loss is decreased by $19.1 \mathrm{~dB}$. It can be seen from the comparison that this design has better insertion loss.

\section{Conclusion}

A band-stop filter with the function of negative group delay is proposed. When the values of elements are different, different types of negative group delay functions such as band pass, high pass, and low pass are realized in the passband of the band-stop filter. The band-pass-type negative group delay is realized in the band-stop filter's passband, and the simulation results are basically consistent with the measured results. The theoretical minimum negative group delay in the passband of the filter is about $-6.03 \mathrm{~ns}$, which improves the delay performance of the communication system. The realization of negative group delay is always at the cost of signal attenuation. In the passband of the designed band-stop filter, the realization of negative group delay only has the insertion loss of $3.5 \mathrm{~dB}$, while in many papers, it is greater than $20 \mathrm{~dB}$ attenuation, which improves the performance of insertion loss. The designed negative group delay band-stop filter has high practical value.

\section{Data Availability}

The data used to support the findings of this study are included within the article.

\section{Conflicts of Interest}

The authors declare that they have no conflicts of interest.

\section{Acknowledgments}

This work was supported by the National Natural Science Foundation of China (Nos. 61871417 and 51809030), the Liaoning Revitalization Talents Program (No. XLYC2007024), the Natural Science Foundation of Liaoning Province (Nos. 2019-MS-024 and 2020-MS-127), and the 
Fundamental Research Funds for the Central Universities (No. 3132021234).

\section{References}

[1] J. Lee, T. C. Lee, and W. J. Chappell, "Lumped-element realization of absorptive bandstop filter with anomalously high spectral isolation," IEEE Transactions on Microwave Theory and Techniques, vol. 60, no. 8, pp. 2424-2430, 2012.

[2] E. J. Naglich, J. Lee, D. Peroulis, and W. J. Chappell, "Extended passband bandstop filter cascade with continuous 0.85-6.6 GHz coverage," IEEE Transactions on Microwave Theory and Techniques, vol. 60, no. 1, pp. 21-30, 2012.

[3] M. K. Mandal, K. Divyabramham, and V. K. Velidi, "Compact wideband bandstop filter with five transmission zeros," IEEE Microwave and Wireless Components Letters, vol. 22, no. 1, pp. 4-6, 2012.

[4] K. Qian and X.-H. Tang, "Compact ultra-wideband lowtemperature co-fired ceramic bandstop filter using semilumped resonators," Electromagnetics, vol. 32, no. 4, pp. 193-199, 2012.

[5] J. A. G. Malherbe and A. Swiatko, "Modified Chebyshev bandstop filter with transmission zeros at real frequencies," Microwave and Optical Technology Letters, vol. 53, no. 1, pp. 177-180, 2011.

[6] J. Lee, E. J. Naglich, and W. J. Chappell, "Frequency response control in frequency-tunable bandstop filters," IEEE Microwave and Wireless Components Letters, vol. 20, no. 12, pp. 669-671, 2010.

[7] Z. P. Wang, J. Kelly, and P. S. Hall, "Reconfigurable bandstop filter with wide tuning range," Electronics Letters, vol. 46, no. 11, pp. 771-772, 2010.

[8] H. S. Lee, D.-H. Choi, and J.-B. Yoon, "MEMS-based tunable LC bandstop filter with an ultra-wide continuous tuning range," IEEE Microwave and Wireless Components Letters, vol. 19, no. 11, pp. 710-712, 2009.

[9] D.-J. Woo, T.-K. Lee, J.-W. Lee, C.-S. Pyo, and W.-K. Choi, "Novel U-slot and V-slot DGSs for bandstop filter with improved Q factor," IEEE Transactions on Microwave Theory and Techniques, vol. 54, no. 6, pp. 2840-2847, 2006.

[10] B. Carey-Smith and P. A. Warr, "Broadband configurable bandstop filter with composite tuning mechanism," Electronics Letters, vol. 40, no. 25, pp. 1587-1589, 2004.

[11] T. Snow, J. Lee, and W. J. Chappell, "Tunable high qualityfactor absorptive bandstop filter design," in Proceedings of the Microwave Symposium Digest IEEE, Montréal, Canada, 2012.

[12] J. Lee, B. Kim, K. Lee, and W. J. Chappell, "Bandwidth-enhanced lumped-element absorptive bandstop filter topology and its application to LTCC bandstop filter design," International Journal of Microwave \& Wireless Technologies, vol. 7, no. 6, pp. 691-698, 2015.

[13] D. R. Jachowski, "Compact frequency-agile, absorptive bandstop filters," in Proceedings of the IEEE MTT-S International Microwave Symposium, pp. 513-516, Long Beach, CA, USA, 2005.

[14] D. R. Jachowski, "Frequency-agile bandstop filter with tunable attenuation," in Proceedings of the IEEE MTT-S International Microwave Symposium, pp. 649-652, Boston, MA, USA, 2009.

[15] D. R. Jachowski, "Cascadable lossy passive biquad bandstop filter," in Proceedings of the IEEE MTT-S International Microwave Symposium, pp. 1213-1216, San Francisco, CA, USA, 2006.

[16] D. K. Choudhary and R. K. Chaudhary, "Compact lowpass and dual-band bandpass filter with controllable transmission zero/center frequencies/passband bandwidth," IEEE Transactions on Circuits and Systems II: Express Briefs, vol. 67, no. 6, pp. 1044-1048, 2020.

[17] D. K. Choudhary, M. A. Abdalla, and R. K. Chaudhary, "Compact D-CRLH resonator for low-pass filter with wide rejection band, high roll-off, and transmission zeros," International Journal of Microwave \& Wireless Technologies, vol. 11, no. 5-6, pp. 509-516, 2019.

[18] D. K. Choudhary and R. K. Chaudhary, "Miniaturized quadband filter with improved selectivity using split ring resonators and metallic strips," International Journal of RF and Microwave Computer-Aided Engineering, vol. 31, no. 10, 2021.

[19] K. J. Kim, M. Di Renzo, H. Liu, T. A. Tsiftsis, P. V. Orlik, and H. V. Poor, "Distributed cyclic delay diversity systems with spatially distributed interferers," IEEE Transactions on Wireless Communications, vol. 18, no. 4, pp. 2066-2079, 2019.

[20] X. Lei, Y. Song, and X. Yao, "Effect of group delay on channel estimation performance in OFDM system," Applied Mathematics \& Information Sciences, vol. 6-3S, no. 3, pp. 1037-1045, 2012.

[21] C. Jabbour, H. Fakhoury, V. T. Nguyen, and P. Loumeau, "Delay-reduction technique for DWA algorithms," IEEE Transactions on Circuits and Systems II: Express Briefs, vol. 61, no. 10, pp. 733-737, 2014.

[22] S. Gupta, D. Sounas, Q. Zhang, and C. Caloz, "All-pass dispersion synthesis using microwave C-sections," International Journal of Circuit Theory and Applications, vol. 42, no. 12, pp. 1228-1245, 2014.

[23] B. Ravelo, "Neutralization of LC- and RC-disturbances with left-handed and NGD effects," Advanced Electromagnetics, vol. 2, no. 1, p. 73, 2013.

[24] T. Eudes and B. Ravelo, "Cancellation of delays in the highrate interconnects with UWB NGD active cells," Applied Physics Research, vol. 3, pp. 81-88, 2011.

[25] R. Gomez-Garcia, J. Munoz-Ferreras, W. Feng, and D. Psychogiou, "Input-reflectionless negative-group-delay bandstop-filter networks based on lossy complementary duplexers," in Proceedings of the 2019 IEEE MTT-S International Microwave Symposium (IMS), pp. 1031-1034, Boston, MA, USA, 2019.

[26] F. Wan, L. Wang, Q. Ji, and B. Ravelo, "Canonical transfer function of band-pass NGD circuit," IET Circuits, Devices and Systems, vol. 13, no. 2, pp. 125-130, 2019.

[27] B. Ravelo, "First-order low-pass negative group delay passive topology," Electronics Letters, vol. 52, pp. 124-126, 2015.

[28] B. Ravelo, "High-pass negative group delay RC-network impedance," IEEE Transactions on Circuits and Systems II: Express Briefs, vol. 64, no. 9, pp. 1052-1056, 2017.

[29] G. Chaudhary, Y. Jeong, and J. Lim, "Microstrip line negative group delay filters for microwave circuits," IEEE Transactions on Microwave Theory and Techniques, vol. 62, no. 2, pp. 234-243, 2014.

[30] L.-F. Qiu, L.-S. Wu, W.-Y. Yin, and J.-F. Mao, "Absorptive bandstop filter with prescribed negative group delay and bandwidth," IEEE Microwave and Wireless Components Letters, vol. 27, no. 7, pp. 639-641, 2017.

[31] G. Chaudhary and Y. Jeong, "Negative group delay phenomenon analysis using finite unloaded quality factor resonators," Progress in Electromagnetics Research, vol. 156, pp. 55-62, 2016.

[32] C.-T. M. Wu and T. Itoh, "Maximally flat negative groupdelay circuit: a microwave transversal filter approach," IEEE Transactions on Microwave Theory and Techniques, vol. 62, no. 6, pp. 1330-1342, 2014. 
[33] G. Chaudhary, “Arbitrary terminated negative group delay circuit with constant signal attenuation and its application to absorptive bandstop filter," in Proceedings of the 2019 49th European Microwave Conference (EuMC), Paris, France, 2019. 